\title{
Speed Controller of Three Phase Induction Motor Using Sliding Mode Controller
}

\author{
Dr.Farazdaq R.Yaseen ${ }^{1}$,Walaa H. Nasser ${ }^{2}$ \\ ${ }^{1,2}$ Control and System Eng. Dep.at Unversity of Technology \\ drfarazdq@gmail.com,walaahussain321@gmail.com
}

\begin{abstract}
A Sliding Mode Control (SMC) with integral surface is employed to control the speed of Three-Phase Induction Motor in this paper. The strategy used is a modified field oriented control to control the IM drive system. The SMC is used to calculate the frequency required for generating three phase voltage of Space Vector Pulse Width Modulation (SVPWM) invertor. When the SMC is used with current controller, the quadratic component of stator current is estimated by the controller. Instead of using current controller, this paper proposed estimating the frequency of stator voltage whereas the slip speed is representing a function of the quadratic current. The simulation results of using the SMC showed that a good dynamic response can be obtained under load disturbances as compared with the classical PI controller; the complete mathematical model of the system is described and simulated in MATLAB/SIMULINK.
\end{abstract}

\section{Index Terms - Induction Motor, Space Vector Pulse Width Modulation, Sliding Mode Control and Field Oriented Control.}

\section{INTRODUCTION}

The three phase Induction Motors (IM) have earned a great interest in the recent years and used widely in industrial applications such as robotics, paper and textile mills and hybrid vehicles due to their low cost, high torque to size ratio, reliability, versatility, ruggedness, high durability, and the ability to work in various environments. Some control methods have been improved to adjust these IM drive systems in high-performance applications [1]. The Field-Oriented Control (FOC) method can be considered as one of the most popular techniques which is used to control the IM. Nowadays, the FOC strategy is the most common method since it ensures the decoupling of the motor flux and torque, this property of FOC gives an assurance that the IM drive sysytem can be controlled linearly as a separately exited DC motor $[1,2,3]$.

Conventional speed control of IM drives with a restricted gain such as PI controllers did not provide an acceptable response for tracking the required trajectory. In order to overcome the parameter variation and/or load changes obstacles, the variable structure control strategy uses the SMC for controlling the AC drive because the SMC provides many advantages, such as: good performance, robustness to the load disturbances, or parameter variation, fast dynamic response, and simple implementation.

The SMC design requires two steps: The first step of this design is selecting the suitable sliding surface $\mathrm{S}(\mathrm{t})$ in terms of tracking error while the second step is designing control signal of the system $u(t)$. Two types of the sliding surface can be recognized in the sliding mode control, the first type is the conventional sliding surface and the other is the integral sliding surface. In this work, an integral sliding surface is presented and its interpretation is compared with the application of the conventional PI controller. 


\section{MATHEMATICAL MODEL OF THE THREE PHASE INDUCTION MOTOR}

The equivalent circuit of IM in the stationary $\mathrm{d}-\mathrm{q}$ reference frame is presented in Fig.1. The IM dynamical model is given by [4].
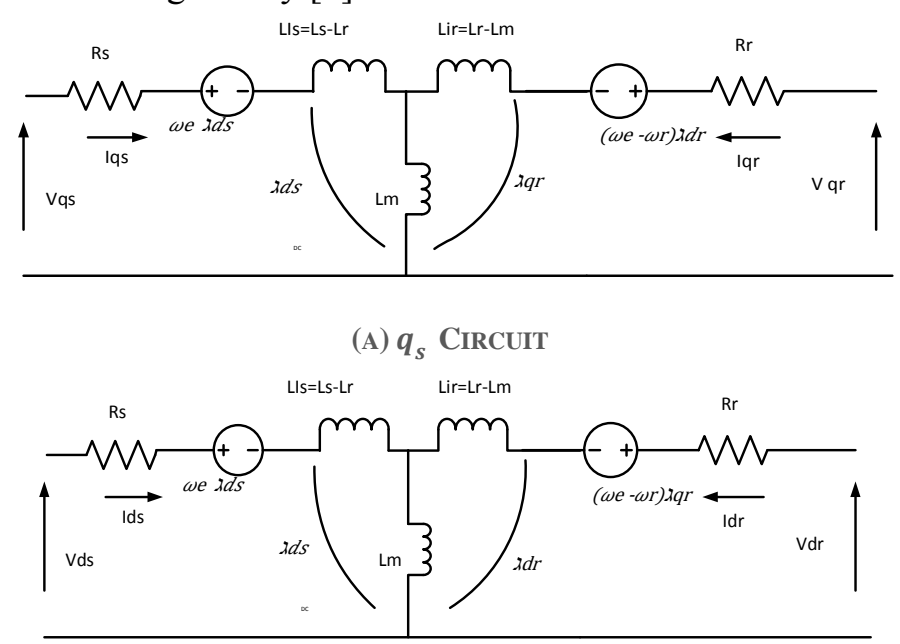

(в) $d_{s}$ CIRCUIT

Fig. 1. IM EQUIVALENT CIRCUIT A) $q_{s}$ CIRCUIT B) $d_{s}$ CIRCUIT

The stationary reference frame can be derived simply by substituting $\omega \mathrm{e}=0$. The corresponding stationary frame equations are presented below:

- Stator equations

$$
\begin{aligned}
& v_{d s}=R_{s} i_{d s}+\frac{d}{d t} \lambda_{d s} \\
& v_{q s}=R_{s} i_{q s}+\frac{d}{d t} \lambda_{q s}
\end{aligned}
$$

- Rotor equations

$$
\begin{aligned}
& 0=R_{r} i_{q r}+\frac{d}{d t} \lambda_{q r}-\omega_{r} \lambda_{d r} \\
& 0=R_{r} i_{d r}+\frac{d}{d t} \lambda_{d r}+\omega_{r} \lambda_{q r}
\end{aligned}
$$

Where $v_{d r}=v_{q r}=0$.

Where $\lambda$ represents the value of the flux linkage, $\mathrm{V}$ represents the voltage; $\mathrm{R}$ is the resistance, $i$ refer to the value of the current and $\omega_{r}$ represents the speed of the rotor. The subscript $r$ denotes the quantity of the rotor, $\mathrm{s}$ refers to the quantity of the stator, and the subscripts $\mathrm{q}$ and $\mathrm{d}$ are symbols for the quadrature axis and direct axis components, respectively in the stationary reference frame. The fluxes are combined with the currents according to the following expressions

$$
\begin{aligned}
& \lambda_{d s}=L_{I s} i_{d s}+L_{M}\left(i_{d s}+i_{d r}\right)=L_{s} i_{d s}+L_{M} i_{d r} \\
& \lambda_{q s}=L_{I s} i_{q s}+L_{M}\left(i_{q s}+i_{q r}\right)=L_{s} i_{q s}+L_{M} i_{q r} \\
& \lambda_{d r}=L_{I r} i_{d r}+L_{M}\left(i_{d s}+i_{d r}\right)=L_{r} i_{d r}+L_{M} i_{d s} \\
& \lambda_{q r}=L_{I r} i_{q r}+L_{M}\left(i_{q s}+i_{q r}\right)=L_{r} i_{q r}+L_{M} i_{q s}
\end{aligned}
$$


Where $L_{M}$ refers to the magnetizing inductance, $L_{r}$ is the rotor inductance and $L_{s}$ is the stator inductance [1].

The equation of electromagnetic torque is given by:

$$
T_{e}=\frac{3}{2}\left(\frac{p}{2}\right)\left(\frac{L_{m}}{L_{r}}\right)\left(\Psi_{d r} i_{q s}-\Psi_{q r} i_{d s}\right)
$$

Where $\mathrm{p}$ refers to the poles number of the motor. The mechanical dynamic equation which relates the motor characteristic speed $\omega_{\mathrm{r}}$ to the torque is:

$$
\mathrm{T}_{\mathrm{e}}-\mathrm{T}_{\mathrm{L}}=\left(\frac{2}{\mathrm{P}}\right) \mathrm{J} \frac{\mathrm{d} \omega_{\mathrm{r}}}{\mathrm{dt}}
$$

Where $T_{L}$ and $\mathrm{J}$ refer to the load torque and the moment of inertia, respectively, $\omega_{s l}$ refer to the slip frequency and $\omega_{r}=\left(\frac{\mathbf{p}}{2}\right) \omega_{m}$ and it can be obtained as:

$$
\omega_{\mathrm{sl}}=\frac{\mathrm{L}_{\mathrm{m}} \mathrm{R}_{\mathrm{r}} i_{q s}}{\Psi_{\mathrm{dr}} \mathrm{L}_{\mathrm{r}}}
$$

The dynamic model of the IM can be expressed in Fig 2.

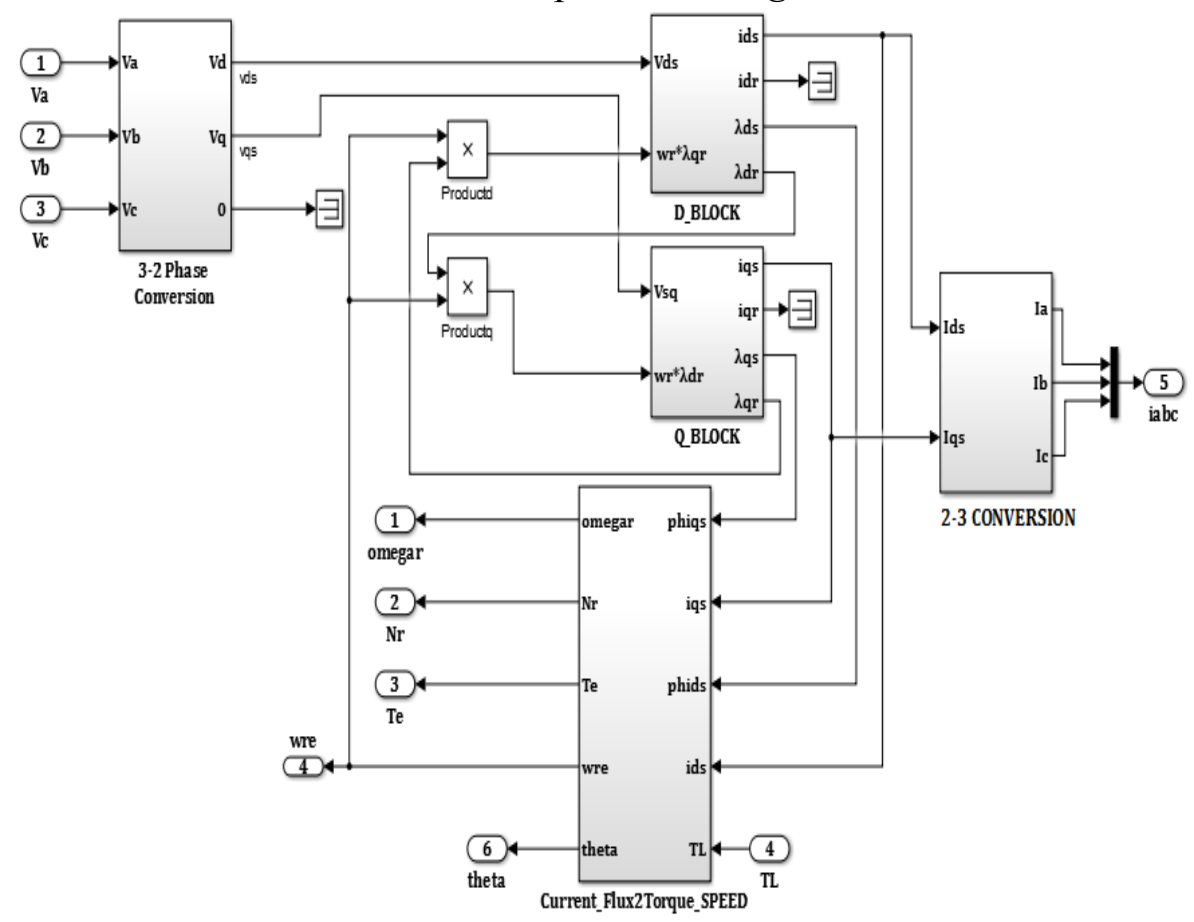

Fig.2 The DynAmic MOdel OF IM.

\section{SPACE VECTOR PLUSE WIDTH MODULATION INVERTER}

This inverter consists of three legs with 6 controlled swithches $\left(S_{1}\right.$ to $\left.S_{6}\right)$. The idea is generation of a vector with amplitude $\mathrm{V}_{\text {ref }}$ which moves with an angle $(\alpha)$ across 6 sectors shown in Fig. 3 . The SVPWM can be performed in the following three steps:

- Step 1. Calculation of Vref and angle $(\alpha)$ from $V_{d}$ and $V_{q}$

- Step 2. Calculation of the time duration $\mathrm{T}_{1}, \mathrm{~T}_{2}$, and $\mathrm{T}_{0}$

- Step 3. Calculation of the switching time of every switching device $\left(S_{1}\right.$ to $\left.S_{6}\right)$ [5]. 


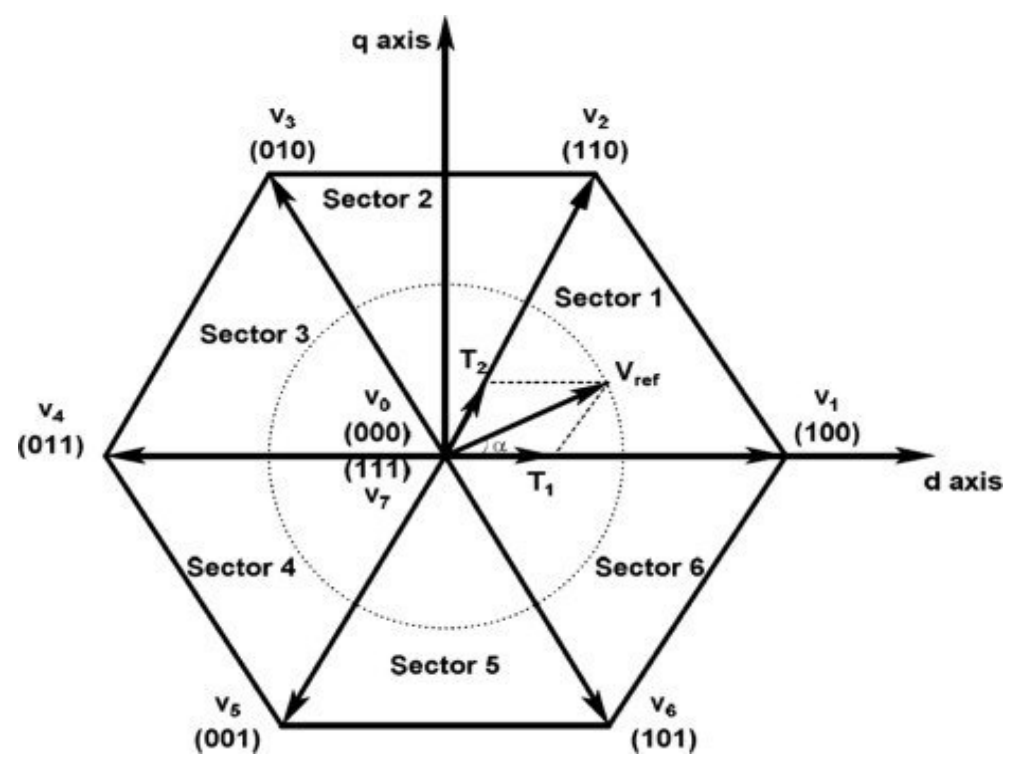

Fig3. THE BASIC SWITCHING VECTORS AND SECTORS.

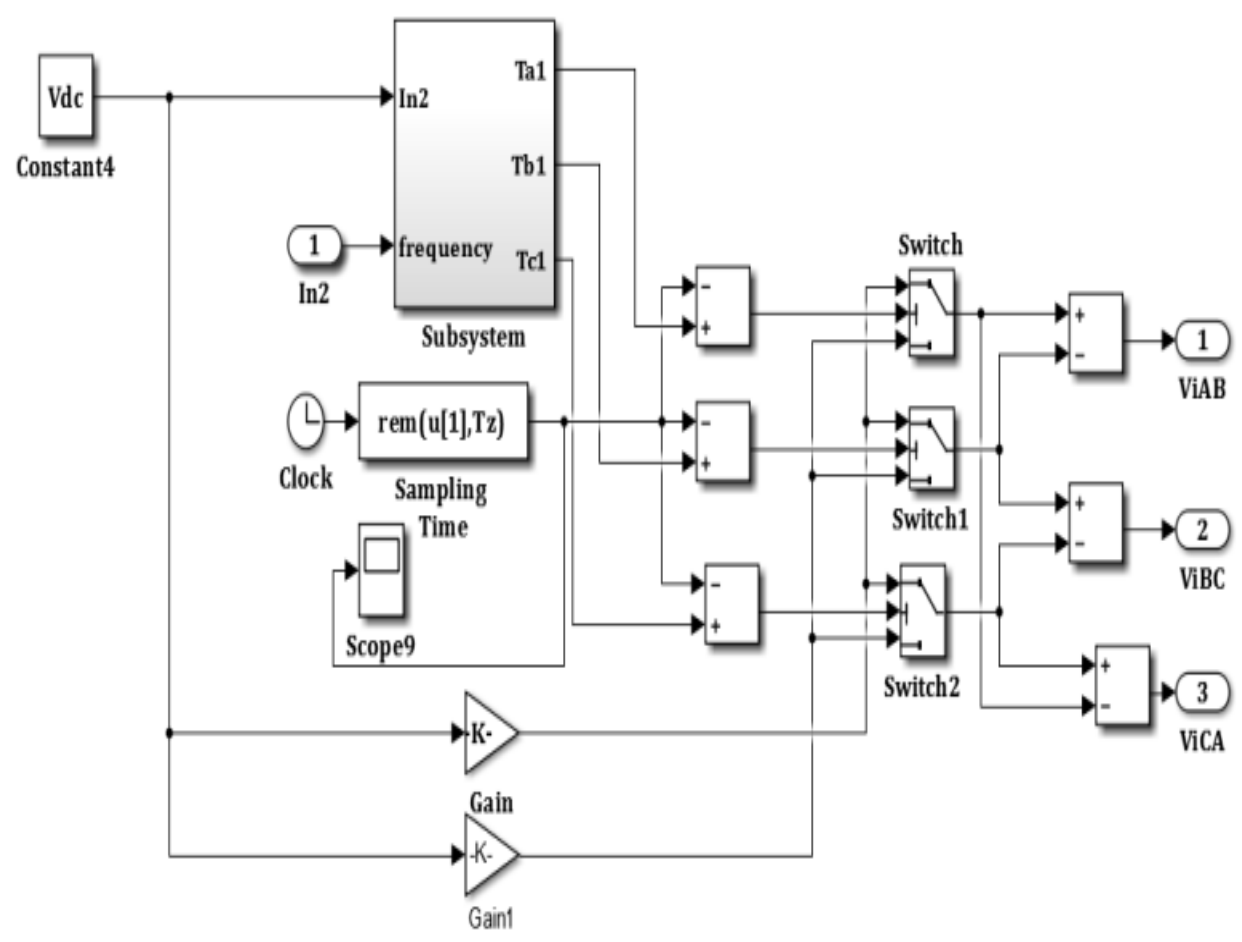

FIG.4 MODEL OF SVPWM.

\section{PI CONTROLLER}

The conventional Proportional plus Integral controller (PI) is a simple speed controller in industrial applications. Under the load condition, the PI controllers try to modify the motor speed to attain the desired system speed. The output of the PI controller is a function of the speed error and the integral of error [6]:

$$
u(t)=K_{p} e(t)+K_{i} \int e(t) d(t)
$$




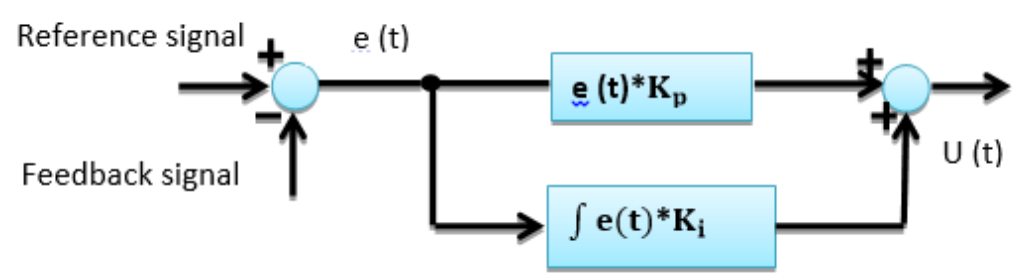

Fig.5 THE BLOCK DIAGRAM OF CONVENTIONAL PI CONTROLLER.

\section{SLIDING MODE CONTROLLER}

The overall block diagram of the IM using (SMC) speed control system is shown in Fig. 6, where the quantity of the actual speed $\left(\omega_{r}\right)$ generated by the IM is compared to the desired value $\left(\omega_{r}^{*}\right)$ to produce an error signal $(e)$.

This error signal and its derivative $(\dot{e})$ are fed to the SMC, which generates a slip frequency and estimates the required frequency for SVPWM where this value is the input to the VSI.

These inputs are used by the VSI for generating a three phase voltage whereas the variation of amplitude and the frequency is done by the SMC.

Generally, the mechanical equation of an IM can be presented as follows [7, 8]:

$$
T_{e}=J \dot{\omega}_{m}+B \omega_{m}+T_{L}
$$

Where B is the friction factor of the IM, $\boldsymbol{T}_{L}$ refers to the external applied load, $\boldsymbol{\omega}_{\boldsymbol{m}}$ refer to the mechanical speed of the rotor, while $\boldsymbol{T}_{\boldsymbol{e}}$ is a point to the electromagnetic torque which can be represented in Eq. (9) as:

$$
T_{e}=\frac{3}{2}\left(\frac{P}{2}\right)\left(\frac{L_{m}}{L_{r}}\right)\left(\lambda_{d r} i_{q s}-\lambda_{q r} i_{d s}\right)
$$

According to the FOC principle, the current component $\boldsymbol{i}_{\boldsymbol{d} \boldsymbol{s}}$ is lined up the direction of the rotor flux vector $\lambda_{r}$ and the current vector $\boldsymbol{i}_{\boldsymbol{q}}$ is lined up perpendicular to it, so the flux vector $\lambda_{\boldsymbol{q} r}=\mathbf{0} \lambda_{\boldsymbol{d r}=}\left|\lambda_{\boldsymbol{r}}\right|$, and Eq.(9) becomes:

$$
T_{e}=\frac{3}{2}\left(\frac{P}{2}\right)\left(\frac{L_{m}}{L_{r}}\right)\left(\lambda_{d r} i_{q s}\right)=K_{T} i_{q s}
$$

Where $\boldsymbol{K}_{\boldsymbol{T}}$ denotes the constant of the torque, and it can be defined as follows:

$$
K_{T}=\frac{3}{2}\left(\frac{P}{2}\right)\left(\frac{L_{m}}{L_{r}}\right)\left(\lambda_{d r} i_{q s}\right)
$$

Using Eq. (14) into (13) then we can get

$$
\mathrm{bi}_{\mathrm{qs}=} \dot{\omega}_{\mathrm{m}}+\mathrm{a} \omega_{\mathrm{m}}+\mathrm{f}
$$

Where $a=\frac{B}{J}, b=\frac{K_{T}}{J}$ and $f=\frac{T_{L}}{J}$

Eq. (16) can be presented with uncertainties $\Delta \boldsymbol{a}, \Delta \boldsymbol{b}$ and $\Delta \boldsymbol{f}$, as follow:

$$
\dot{\omega}_{m}=-(a+\Delta a) \omega_{m}-(f+\Delta f)+(b+\Delta b) i_{q s}
$$

The error of the tracking speed can be define as

$$
e_{(t)=\omega_{m}}(t)-\omega_{m}^{*}(t)
$$

Where $\omega_{m}^{*}(t)$ is a point to reference speed of the rotor, then by taking the derivative of the pervious equation with respect to time it produces: 


$$
\dot{e}_{(t)=} \dot{\omega}_{m}(t)-\dot{\omega}_{m}^{*}(t)=-a e(t)+u(t)+d(t)
$$

Where

$$
u(t)=b i_{q s}-a \dot{\omega}_{m}-f-\dot{\omega}_{m}^{*}(t)
$$

While the equation of the uncertainties can be represented as:

$$
\mathrm{d}(\mathrm{t})=-\Delta \mathrm{a} \dot{\omega}_{\mathrm{m}}-\Delta \mathrm{f}(\mathrm{t})-\Delta \mathrm{bi}_{\mathrm{qs}}(\mathrm{t})
$$

The sliding surface $\mathrm{S}(\mathrm{t})$ with the integral component can be defined as:

$$
S(t)=e(t)-(k-a) \int e(t) d(t)
$$

Where $\boldsymbol{k}$ is a constant gain and it is defined as $k<0$. When the sliding mode will be occur on the sliding surface, then $S(t)=\dot{S}(t)=0$, therefor; the dynamical behavior of the tracking problem can be illustrated as :

$$
\dot{\mathrm{e}}_{(\mathrm{t})}=(\mathrm{k}-\mathrm{a}) \mathrm{e}(\mathrm{t})
$$

The design of the variable structure speed controller will be as

$$
u(t)=k e(t)-\beta \operatorname{sgn}(S)
$$

Where $\beta$ is known as the switching gain, $S$ refer to the sliding variable while the $\operatorname{sgn}()$ refer to the sign function which can be described as:

$$
\operatorname{Sgn}(S(t))= \begin{cases}1 & \text { if } S(t)>0 \\ -1 & \text { if } S(t)<0\end{cases}
$$

the tracking of the speed trajectory can be obtained, when the following assumption is formulated :

- The value of the gain $k$ should be chosen so that the term $(k-a)$ is precisely negative, so, thus $k<0$.

- $\quad$ The value of the gain $\beta$ should be chosen so that $\beta \geq|d(t)|$ for all time.

Once this assumption is confirmed, then the control law in Eq.(24) will be lead to the mechanical speed of the rotor [9].

Finally the quadrature current $i_{q s}$ can be attained by the direct substituting of $\mathrm{u}(\mathrm{t})$ expressed in Eq. (24) into the previous Eq. (16) [10].

$$
i_{q s}=\frac{1}{b}\left(k e(t)-\beta \operatorname{sgn}(S)+a \omega_{m}^{*}+\dot{\omega}_{m}+f\right)
$$

From Eq. (11) and (26)

$$
\omega_{\mathrm{sl}}=\frac{c}{b}\left(k e(t)-\beta \operatorname{sgn}(S)+a \omega_{m}^{*}+\dot{\omega}_{m}+f\right) i_{q s}
$$

Where $\mathrm{c}$ is the constant, so by using the above sliding mode design, the speed tracking problem will be solved under the load disturbance. In practice, chattering is obejectionable effect, since it include high control activity and furthermore high frequency dynamics may be excited. This situation can be avoided by smoothing out the control chattering within a thin boundary layer of thickness.

by this method, some modification will be performed on Eq. (27) in order to smooth the control signal. The chattering phenomenon is eliminated in the SMC systems by using the saturation functions $\boldsymbol{s a t}($ ) instead of the sign function $\boldsymbol{s g n}($ ) $[10,11]$. 


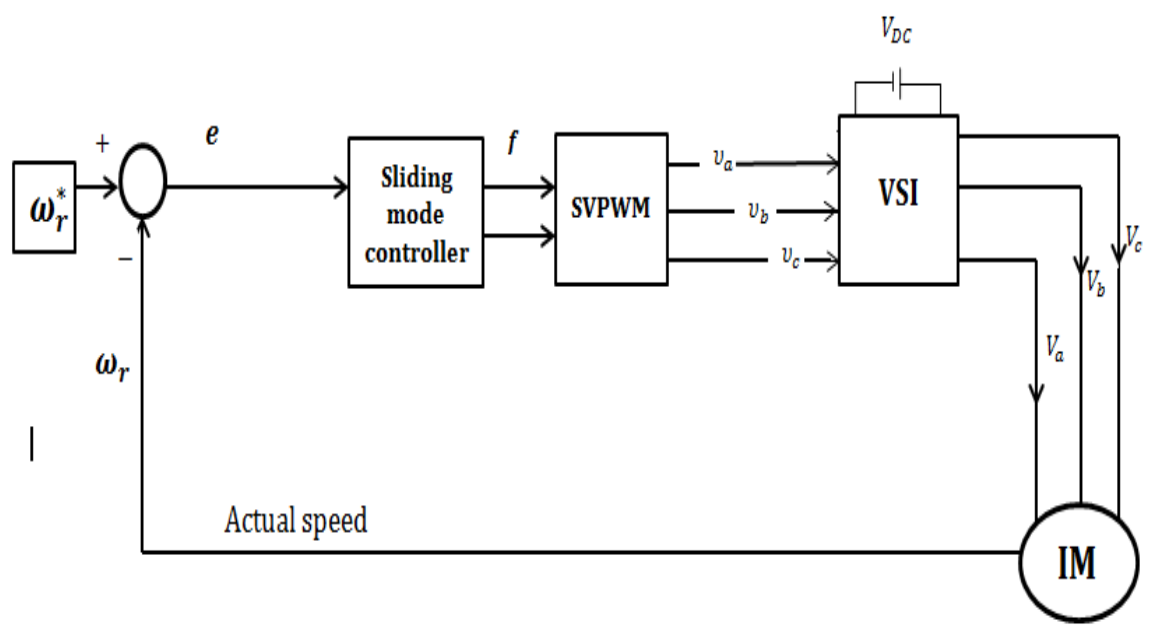

FIG.6 SMC DIAGRAM

\section{SIMULATION RESULTS}

The modelling and the simulation of the controller is carriedout on IM with the parameters shown in table 1. Simulation results for vector control of IM were carried out using the conventional PI controller, as shown in Fig.7 below, where the reference speed of IM is $1500 \mathrm{rpm}$; the rated load condition is changed in steps from 0 up to $2 \mathrm{~N} . \mathrm{m}$ at a time of $1 \mathrm{sec}$. The trial and error tuning method is used for tuning the PI controllers used in vector control where the value of the PI controller gains are $\mathrm{Kp}=0.0018$ and $\mathrm{Ki}=0.12$, Fig. 7 demonstrate the IM speed response using the PI controller, where the motor speed is dropped and the used controller raise it to follow the reference speed.

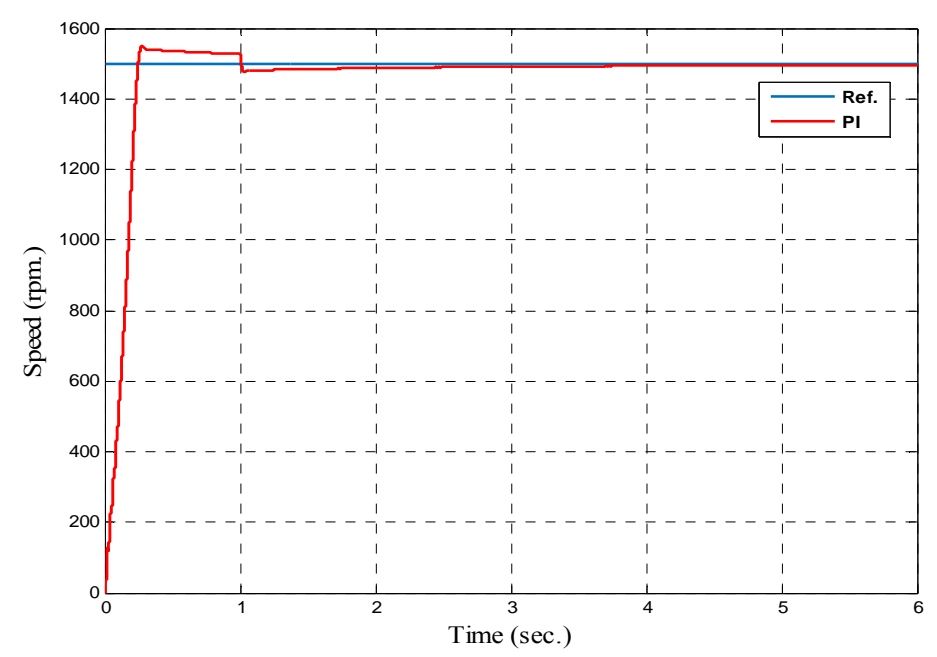

FIG.7 PI SPEED RESPONSE.

Fig. 8 shows the speed response of the SMC. Figures 9 and 10 show the current and the torque responses of IM when the speed is varied from 1500 to $1377 \mathrm{rpm}$ at a time of $1 \mathrm{sec}$. after applying external load torque $=2 \mathrm{~N} . \mathrm{m}$ with SMC.

The speed of the rotor $\omega_{r}$ is compared to the reference speed $\omega_{r}^{*}$, and the term of the result in error is processed by the sliding mode controller, which will generates the current $i_{q s}^{*}$ in the q axis reference frame, then the slip frequency is calculated to generate the required frequency. The output frequency is given to the VSI which converts this frequency into three phase voltage signal and these signals are given to the IM which controls the speed and torque. 
The speed response of SMC has a small overshot and it is clear that the load change does not extend the proposed control performance. The system maintains robustness against the effect of the load change.

The phase plane portrait of the speed error is shown in Fig.11. It is clear that the error trajectory moves toward the equilibrium point and after loading of IM the trajectory leaves the equilibrium point and the SMC will overcome this change.

Fig. 11 shows the system trajectory that starts from the point $(e, \dot{e})=(1500,0)$ and moves towards the equilibrium point $(0,0)$ with some delay. At loading instant, the motor speed is decreased and the error is increased, which affects the system trajectory and leaves the equilibrium point, the used controller tries to return it back to that point.

Fig. 12 shows the speed responses of IM with the conventional PI controller and the SMC. At the load instant, the motor speed is decreased. The obtained results show that the SMC can provide better and robust speed tracking performance when it is compared with the conventional PI controller; it is clearly displays that the system using SMC can manage under applied load as compared with the PI controller, the system clarifies that the steady state error is reduced to possible minimum value with less overshoot.

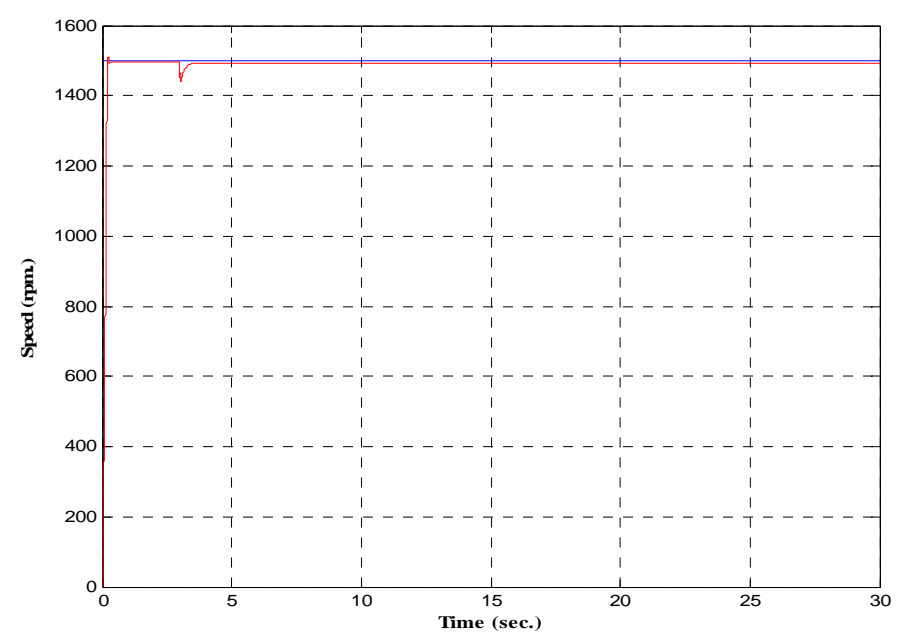

Fig.8 SMC SPEED RESPONSE.

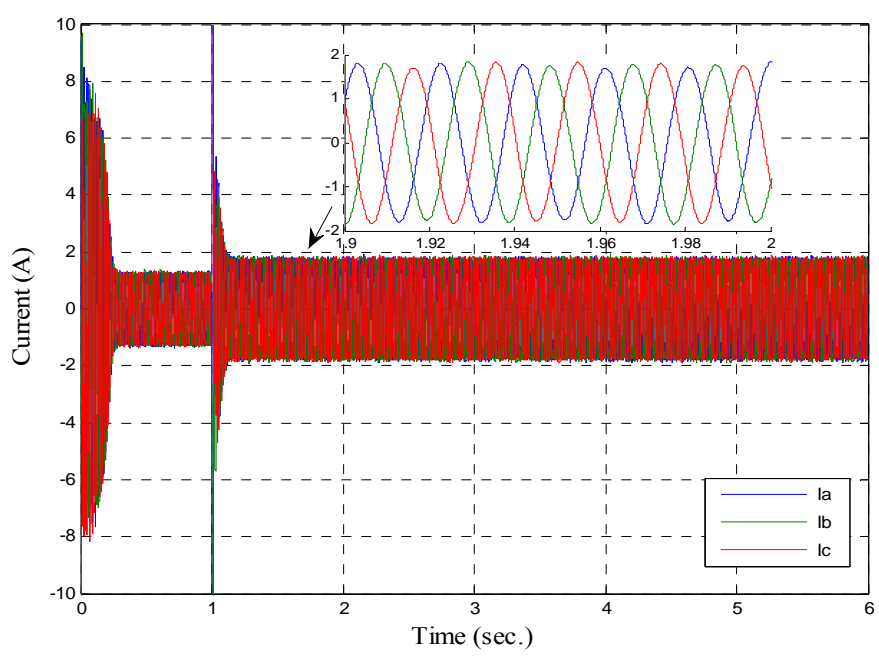

FIG.9 SMC CURRENT RESPONSE 


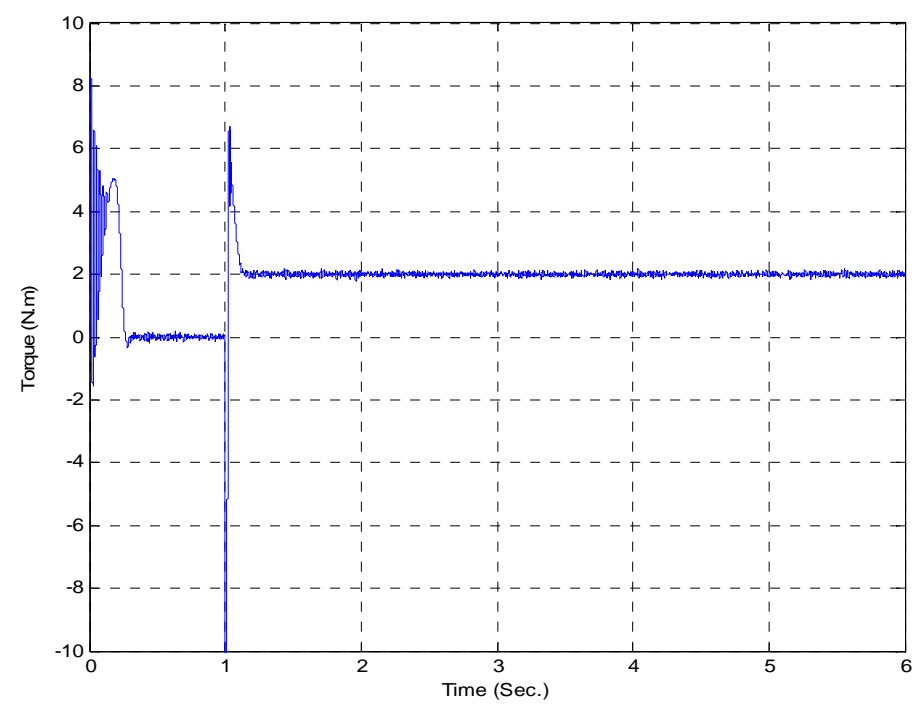

FIG.10 SMC TORQUE RESPONSE

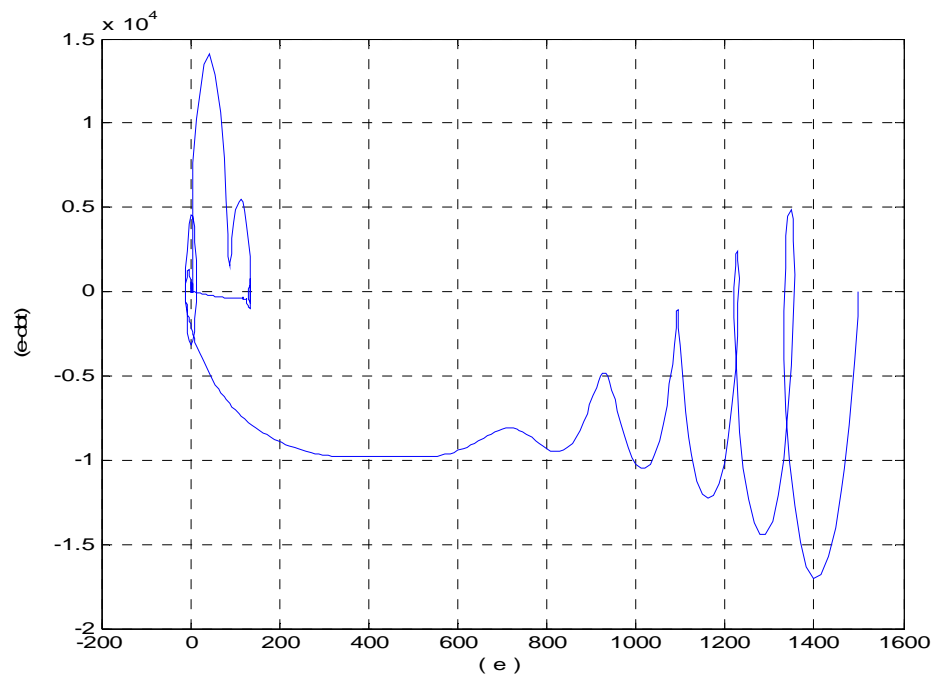

FIG. 11 THE PHASE PLANE PORTRAIT OF THE SPEED ERROR.

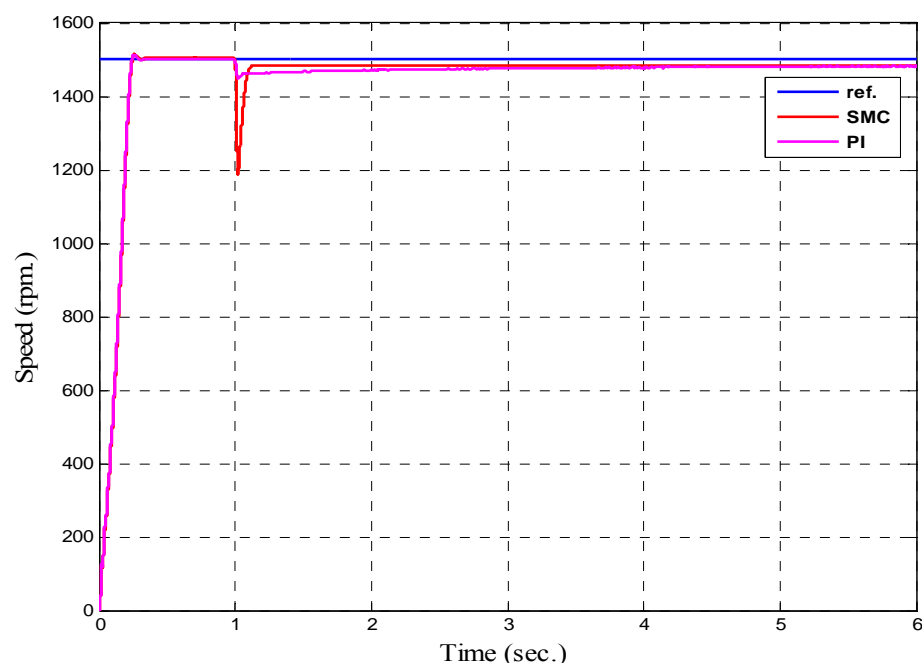

FIG.12 THE SPEED RESPONSE COMPARISON OF PI AND SMC 
TABLE1. PARAMETERS OF IM.

\begin{tabular}{ccc}
\hline Parameters & Values & Units \\
\hline Voltage & 200 & $\mathrm{~V}$ \\
Stator resistance (Rs) & 6.03 & $\Omega$ \\
Rotor resistance (Rr) & 6.085 & $\Omega$ \\
Stator inductance (Ls) & 0.4893 & $\mathrm{H}$ \\
Rotor inductance (Lr) & 0.4893 & $\mathrm{H}$ \\
Mutual inductance (Lm) & 0.4503 & $\mathrm{H}$ \\
Poles & 4 & --- \\
Moment of Inertia & 0.00488 & $\mathrm{Kg} . \mathrm{m}^{2}$ \\
\hline
\end{tabular}

\section{CONCLUSION}

In this paper, an adaptive SMC with an integral sliding surface is presented and the FOC strategy is used. The proposed SMC will overcome the load change faster than the conventional PI controller with zero steady state error. SMC consists of two parts. The first part is reaching phase that moves the system from the initial condition to the sliding surface. While the second part is sliding phase which tries to fix the system to sliding toward the equilibrium point. The frequency result from the controller increases when the load is applied, while the motor speed is decreases and the used controller attempts to raise it to reference speed. Chattering that occurs in the sliding phase can be overcome by using the saturation function. Therefore, the SMC is an intelligent controller operating under uncertainty conditions and deals with the system changes quickly.

In conclusion, we demonstrated that the proposed SMC speed controller for the closed loop operation of the IM drive system has improved performance over the conventional PI controller with a better speed response, higher effectiveness, and good robustness levels.

\section{NOMENCLATURE}

$\begin{array}{clc}\mathrm{B} & \text { coefficient of viscous friction } & \mathrm{Nm} /(\mathrm{rad} / \mathrm{s}) \\ i_{d s}, i_{q s} & \mathrm{~d} \text { and q axis components of the stator currents } & \mathrm{Amp} . \\ \mathrm{J} & \text { moment of Inertia } & \mathrm{Kg} \cdot \mathrm{m}^{2} \\ L_{S}, L_{r} \& L_{m} & \text { stator, rotor and mutual inductances } & \mathrm{H} \\ \mathrm{P} & \text { number of poles. } & \mathrm{None} \\ R_{S} & \text { stator resistance of IM } & \Omega \\ R_{r} & \text { rotor resistance of IM } & \Omega \\ T_{e} & \text { torque developed in the IM } & \mathrm{N} . \mathrm{m} \\ T_{L} & \text { external load torque } & \mathrm{N} . \mathrm{m} \\ v_{d s}, v_{q s} & \text { stationary direct and quadrature stator voltage } & \text { Volt. } \\ \boldsymbol{\beta} & \text { Swtiching gain } & \mathrm{None} \\ \Omega \mathrm{rr} & \text { rotor speed } & \mathrm{rad} / \mathrm{sec} . \\ \lambda d_{r} \text { and } \lambda q_{r} & \text { the d and q axis components of the rotor fluxes } & \mathrm{Wb}\end{array}$




\section{Acronyms}

\section{Acronyms}

FOC
IM
PWM
SMC
SVPWM

\section{Definition}

Field Oriented Control

Induction Motor

Pulse Width Modulation

Sliding Mode Controller

Space-Vector Pulse Width Modulation

\section{REFERENCES}

1) Barambones, O., Garrido, A. J., \& Maseda, F. J. (2007). Integral sliding-mode controller for induction motor based on field-oriented control theory. IET Control Theory \& Applications, 1(3), 786-794.

2) Hashim A .O., Martino O. A., Shamboul A. M. , Matthew W. D. , 2011, Combined Sliding Mode Control with a Feedback Linearization for Speed Control of Induction Motor, Iraq J. Electrical and Electronic Engineering,Vol.7.

3) Patakor, F. A., Sulaiman, M., \& Ibrahim, Z. (2011, December). “Adaptive Sliding Mode for indirect field oriented controlled of induction motor". In Research and Development (SCOReD), 2011 IEEE Student Conference on (pp. 289-293). IEEE.

4) Mikhael .H, Jalil. H., Ibrahim. I , 2016, Speed Control of Induction Motor using PI and V/F Scalar Vector Controllers , International Journal of Computer Applications (0975 - 8887) Volume 151 - No.7 .

5) Jung, J. W., \& DStudent, P. H. (2005). PROJECT\# 2Space vector PWM inverter. Mechatronic Systems Laboratory, Dept. of Electrical and Computer Eng. The Ohio State University.

6) Menghal, P. M., Laxmi, A. J., \& Anusha, D. (2014). "Speed control of induction motor using fuzzy logic controller". i-Manager's Journal on Electrical Engineering, 8(2), 21.

7) Bennassar. A., Abbou. A., Akherraz. M., Barara. M., 2013, Fuzzy Logic Speed Control for Sensorless Indirect Field Oriented of Induction Motor Using an Extended Kalman Filter, International Review of Automatic Control (I.RE.A.CO.), Vol. 6, N. 3.

8) Patakor, F. A., Sulaiman, M., \& Ibrahim, Z. (2010, December). "Performance of sliding mode control for three phase induction motor”. In Science and Social Research (CSSR), 2010 International Conference on (pp. 554-559). IEEE.

9) Sobha C. Barik, May 2007) "Sliding mode vector Control of three phase induction motor." Master of Technology in Power Control and Drives', Department of Electrical Engineering.

10) Oliveira, C. M., Aguiar, M. L., Pereira, W. C., Castro, A. G., Almeida, T. E., \& Monteiro, J. R. (2016, November). Integral sliding mode controller with anti-windup method analysis in the vector control of induction motor. In Industry Applications (INDUSCON), 2016 12th IEEE International Conference on (pp. 1-7). IEEE.

11) Sulaiman, M. A. R. I. Z. A. N., Patakor, F. A., \& Ibrahim, Z. U. L. K. I. F. I. L. I. E. (2014). "New methodology for chattering suppression of sliding mode control for three-phase induction motor drives". WSEAS Trans. Syst. Control, 9, 1-9. 